\title{
Aroma characteristics and volatile compounds of distilled Crystal grape spirits of different alcohol concentrations: wine sprits in the Shangri-La region of China
}

\author{
Xiao-Feng $\mathrm{WEI}^{1,2}$, Xue-Lei $\mathrm{MA}^{3}$, Jian-Hong $\mathrm{CAO}^{4}$, Xiang-Yu SUN ${ }^{1,5}$, Yu-Lin FANG ${ }^{1,2 *}$
}

\begin{abstract}
Aroma composition is critical to the quality of distilled spirits while the alcohol concentration could have a great effect on the variety and content of aromatic substances. In order to clarify the effect of alcohol concentration on the formation of the aroma composition, volatile compounds in Crystal distilled grape spirits with different alcohol concentrations were analyzed using the Stir bar sorptive extraction (SBSE) technique combined with GC-MS. Characteristic aromas, principal components and odor profiles were also explored. Eighty-six compounds were identified in Crystal distilled grape spirits and 19 compounds were the same for the 4 samples with different alcohol concentrations. The species and contents of esters increased significantly along with the alcohol concentration increasing, while the acid content decreased. No significant change in the volatile alcohol and carbonyl contents was observed, and no terpene was detected in the spirits of $80 \%$ vol alcohol content. Fruity was the strongest aroma in the 6 aromatic series of odor, followed by floral and fatty. The $77 \% \mathrm{vol}$ alcohol distilled grape spirits showed the most fragrant and balanced aroma.
\end{abstract}

Keywords: alcohol; aroma; Crystal distilled grape spirits; odor; PCA.

Practical Application: Improving the quality of distilled grape spirits in high altitude areas.

\section{Introduction}

Aromatic and volatile compounds are important sensory indicators and quality parameters for alcoholic beverages (Janáčová et al., 2008; Saénz-Navajas et al., 2013). Distilled grape spirits, which can be turned into brandy after vintage oak barrels and blending, have now become increasingly popular and important in the world (Soto et al., 2008; Zhang et al., 2013a). On the whole, the imports and exports of distilled grape spirits have been increasing in the last 20 years in China (Customs Information China, 2016). The type, content and sensory threshold of the aromatic substances are the primary factors that affect the quality of brandy. These factors also determine the flavor, representativeness and sensory quality of distilled grape spirits (Caldeira et al., 2002; Zhao et al., 2009). Grape varieties, wine-making and distillation factors (such as the temperature, yeast and oak treatment) jointly influence the volatile substances in spirits (Fan et al., 2006; Satora \& Tuszynski, 2010). Aroma properties of grape spirits are attaching more and more attentions around the world (Diéguez et al., 2003, 2005). Volatile compositions and sensory properties of spirits made out of other plant fruits, such as banana, cane and potato, had also been studied (Rota et al., 2013; Okutsu et al., 2015). However, the volatile composition of Chinese spirits is still an area that is under-researched (Zhao et al., 2012).
Alcohol is a principal element of alcoholic beverages. It affects the sensory profile and is often used to classify alcoholic products (King et al., 2013). No less than $8.5 \% \mathrm{v} / \mathrm{v}$ alcohol content is required for wine while the alcohol concentration in brandy is usually above $40 \%$ vol (King et al., 2013; Soto et al., 2008). The highest ethanol content for spirits is $86 \%(\mathrm{v} / \mathrm{v})$ (Porto \& Decorti, 2010). Alcohol in wine is known to reduce 'astringency' (Fontoin et al., 2008; King et al., 2013); to increase clarity, density and viscosity; and also could to provide a sharp mouthfeel. Low alcohol wine is often considered unripe with harsher tannins and has been criticized for lacking the fullness characteristics of a 'full strength' counterpart (Pickering et al., 1998), while high alcohol wine is often thought to be riper with smoother tannins (King et al., 2013). The effect of alcohol on the volatile aroma composition in wine has been reported (Knoll et al., 2011), and studies of brandy aroma have mainly been focused on the change of components during the distillation process (Caldeira et al, 2016; Fiches et al., 2013; Geroyiannaki et al., 2007). However, differences in the components in distilled grape spirits with different alcohol concentrations have not yet been reported.

The Shangri-La region includes 9 prefectures (or cities) in southwest China. It is currently considered to be an excellent area for high quality highland wine production (Figure 1). 


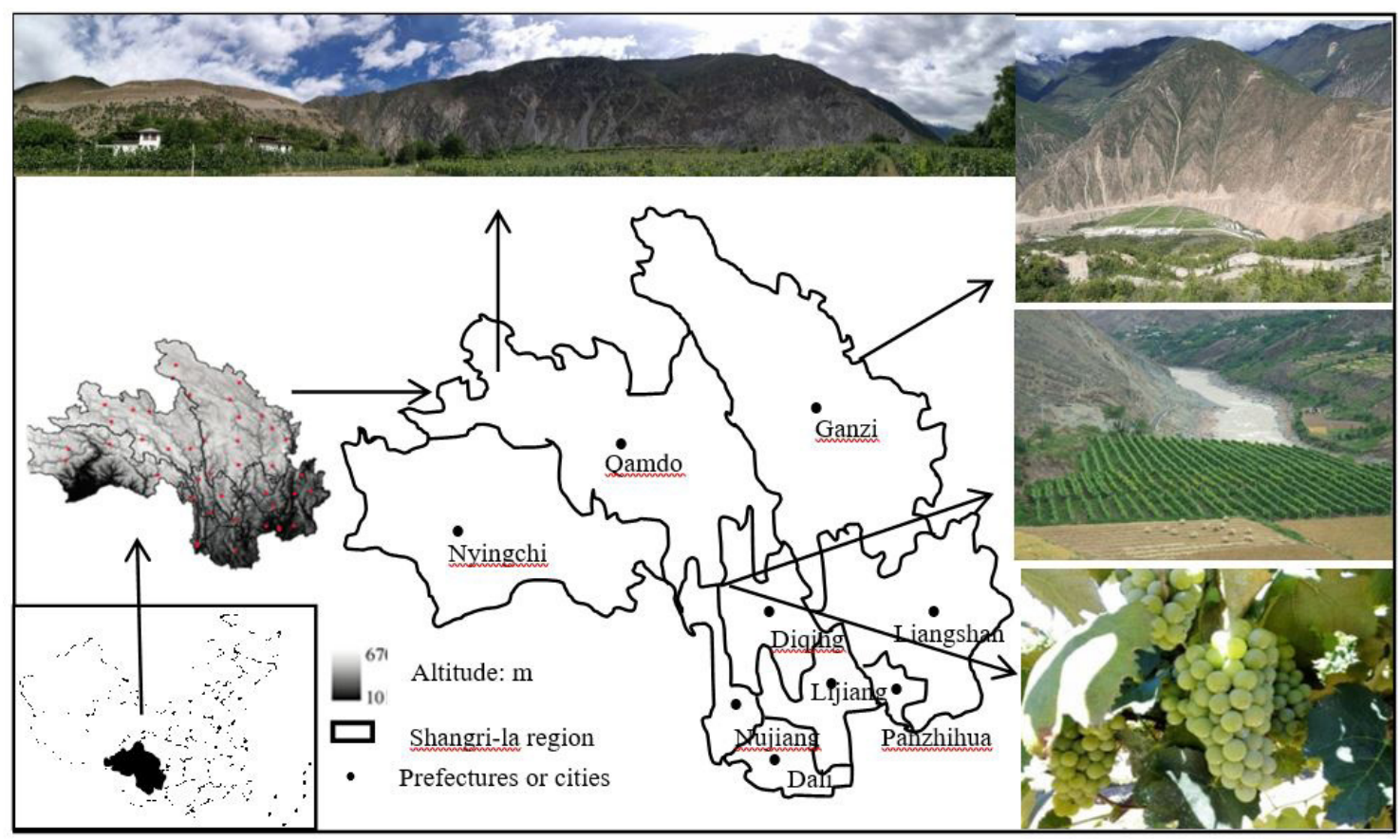

Figure 1. Geographical location of Shangri-La region.

With long sunshine duration (2000-2600 h), large diurnal temperature differences and relatively cold temperatures during the fruit maturation period, climatic conditions in this region are conducive to the accumulation of aromatic and phenolic substances in grape (Zheng et al., 2008). Except that, the intense ultraviolet radiation is beneficial for fruit coloration. And the huge elevation gap (1700-3000 m) had created excellent conditions for the production of wine in different styles and characteristics (Wang et al., 2013). Unlike most grape production areas of China, the climate in the Shangri-La region is relatively dry and rainless (Zhang et al., 2013b). Moreover, brown and stony soil with abundant organic matter and pebbles is beneficial to root extension and plant growth (Zhang et al., 2008).

Crystal grape is an important variety of Euramerican hybrid grapes for the production of distilled grape spirits in China. The Crystal grape in China is allegedly said to be introduced by 16 French missionaries in the 1940s. It is one of the varieties with the longest cultivation history, the widest distribution and the largest planting area in the Shangri-La region. In addition, it has the characteristics of high quality and yield, good flavor, wide adaptability, good resistance to drought, low temperature and disease (Zhang et al., 2015).

In this study, the aroma components in Crystal distilled grape spirits with 4 different alcohol concentrations from Shangri-La region were analyzed. PCA was employed to determine the potential relationships among the measured parameters and to reveal the components that could be responsible for the aroma content in distilled grape spirits. The characteristic aroma and its variations were analyzed while the odor profiles were also evaluated. The objective was to analyze the influence of alcohol concentration on the aroma characteristics and volatile compounds in Crystal distilled grape spirits, hoping to provide a reference for the aroma quality improvement of distilled grape spirits in high altitude areas.

\section{Materials and methods}

\subsection{Plant materials}

The Dong-Feng Farm $\left(24^{\circ} 18^{\prime} 23^{\prime \prime} \mathrm{E}, 03^{\circ} 23^{\prime} 55 \mathrm{~N}, 1431\right.$ meters above sea-level), which is located in the Mi-Le County, Yunnan Province, was taken as the experimental site. Grapevines were planted in 1995 and growth in a north-south line with the spacing of $1.5 \mathrm{~m} \times 2.8 \mathrm{~m}$. Organic manure was applied under general management. Crystal grape materials were collected from the grapevines in July 15, 2014 when the grapes got ripe (with sugar content above $150 \mathrm{~g} / \mathrm{L}$ ).

\subsection{Fermentation and distillation details}

The Crystal grapes harvested in September, 2014 were firstly fermented into dry red wine, fermentation details were shown in Table 1. Wines were then directly distilled in Alambic Charentais Pot Still (2-tons volume) without the addition of potassium metabisulfite. There were 3 stages in the distillation process, during which the alcohol content was advanced from $10 \% \mathrm{vol}$ to $20-30 \% \mathrm{vol}$, then from $20-30 \% \mathrm{vol}$ to $40-50 \% \mathrm{vol}$, finally from $40-50 \% \mathrm{vol}$ to $60-80 \% \mathrm{vol}$. Then the original products of 3 different alcohol content ranges were mixed in different proportions in oak barrels to obtain spirits of certain alcohol concentrations (51\%vol, $65 \% \mathrm{vol}, 77 \% \mathrm{vol}, 80 \% \mathrm{vol}$, respectively). All the spirits of different alcohol content were made from the same homogenized grapes, Crystal grapes. And the fermentation processes were carried out in the totally same containers and 
Table 1. Fermentation details of the dry red wine.

\begin{tabular}{|c|c|c|}
\hline Items & & \\
\hline \multirow[t]{3}{*}{ Cold Soaking } & Period & $2-3 d$ \\
\hline & Temperature & $15-18^{\circ} \mathrm{C}$ \\
\hline & Circulation & 1-2 times per day \\
\hline \multirow[t]{4}{*}{ Fermentation Temperature } & Inoculation & $18-20^{\circ} \mathrm{C}$ \\
\hline & Prophase & $20-25^{\circ} \mathrm{C}$ \\
\hline & Metaphase & $26-28^{\circ} \mathrm{C}$ \\
\hline & Anaphase & $26-29^{\circ} \mathrm{C}$ \\
\hline Systemic Circulation & Start Time & Specific gravity reaches 1020 \\
\hline \multirow[t]{3}{*}{ Post-fermentation Maceration } & Period & $5-7 \mathrm{~d}$ \\
\hline & Temperature & $26-29^{\circ} \mathrm{C}$ \\
\hline & Circulation & 1-2 times per day \\
\hline \multirow[t]{4}{*}{ Ingredients } & Pectinase & EXV Pectinase;20-30ppm \\
\hline & Sulphurous Acid & $0.6-0.8 \mathrm{~L} / \mathrm{T}$ \\
\hline & Oak Chips & $1.7 \mathrm{~kg} / \mathrm{t}$ grape \\
\hline & Yeast & BDX Yeast \\
\hline
\end{tabular}

conditions in the Shangri-La Winery Co., LTD (Diqing Tibetan Autonomous Prefecture, Yunnan Province, China). Temperature was kept between $12-15^{\circ} \mathrm{C}$ in the whole process. The distilled grape spirits were bottled in $750 \mathrm{~mL}$ bottles and preserved below $10^{\circ} \mathrm{C}$ until analysis. For each kind of distilled spirits with 4 different alcohol concentrations, 3 bottles of the corresponding products were taken as biological repeats.

\subsection{Chemicals and reagents}

Pure standards were purchased from the Sigma-Aldrich Chemical Co. (Shanghai, China). The solvents were spectrophotometric grade from J\&K Co. Ltd. (Beijing, China). The DB-Wax Gas Chromatograph Column was purchased from J \& W Scientific, Rancho Cordova, CA. All other chemicals were of analytical grade.

\subsection{Sample preparation with SBSE}

The SBSE procedure was based on prior studies with some modifications (Delgado et al., 2010). All samples with different alcohol concentrations were diluted to $11 \%$ vol, then took $10 \mathrm{~mL}$ sample after dilution into a $15 \mathrm{~mL}$ sample bottles with $2 \mathrm{~g} \mathrm{NaCl}$ and $10 \mu \mathrm{L} 2$-Octanol (internal standard). The closed sample bottles were placed on a PC-420D magnetic stirrer (Corning, New York, US) at room temperature for $60 \mathrm{~min}$ for extraction, and the rotor speed was $1100 \mathrm{r} / \mathrm{min}$. After extraction, the stir bar (20 mm $\times 0.5 \mathrm{~mm}$, GERSTEL, der Ruhr, Germany) was removed with a tweezers, then blotted with filter paper, and finally placed into a glass thermal desorption tube and extracting fiber was added. Samples were prepared in triplicate.

\subsection{Gas Chromatography-Mass Spectrometry (GC-MS) analyses}

Compound profiling was performed using an Agilent 6890 GC-MS system equipped with an Agilent 5975 mass spectrometer and an HP-INNOWAX capillary column $(60 \mathrm{~mm} \times 0.25 \mathrm{~mm})$ with 0.25-mm film thickness ( $\mathrm{J} \& \mathrm{~W}$ Scientific, Folsom, CA) as described previously (Varela et al., 2012). The flow rate of the carrier gas (helium) was $1 \mathrm{~mL} / \mathrm{min}$. The temperature program was raised from $40{ }^{\circ} \mathrm{C}(3 \mathrm{~min}$ hold $)$ to $160^{\circ} \mathrm{C}$ at the speed of $4{ }^{\circ} \mathrm{C} / \mathrm{min}$, then from $160{ }^{\circ} \mathrm{C}$ to $230^{\circ} \mathrm{C}$ at $7{ }^{\circ} \mathrm{C} / \mathrm{min}$, and held at $230^{\circ} \mathrm{C}$ for $8 \mathrm{~min}$. The operating conditions were as follows: capillary direct interface temperature, $230{ }^{\circ} \mathrm{C}$; heater valve temperature, $245^{\circ} \mathrm{C}$; transfer line temperature, $255^{\circ} \mathrm{C}$, The trap temperature was set at $-30^{\circ} \mathrm{C}$ for starting temperature and then ramped to $255^{\circ} \mathrm{C}$ at $40^{\circ} \mathrm{C} / \mathrm{min}$. The samples were exposed to $270^{\circ} \mathrm{C}$ and desorbed in the GC inlet at the flow rate of $45 \mathrm{~mL} / \mathrm{min}$ for $4 \mathrm{~min}$. The split ratio was adjusted to 3:1. The mass spectra were scanned at $70 \mathrm{eV}$ in the acquisition mass range $45-450 \mathrm{amu}$ at $1 \mathrm{~s}$ intervals. The filament emission was set at $0.2 \mathrm{~mA}$ with the ion source at $230{ }^{\circ} \mathrm{C}$ and a detector voltage of $350 \mathrm{~V}$. Samples were analyzed in triplicate.

\subsection{Principal Component Analysis (PCA)}

PCA was performed and a correlation matrix was listed according to the correlation coefficients using XLStat software. Characteristic roots and their corresponding vectors were calculated and several of them were selected with accumulative contributions above $90 \%$. Principal component values were calculated according to the standard values of relative content, characteristic roots and vectors. A scatter diagram was then produced.

\subsection{Statistical analysis}

A statistical elaboration of the data was performed using the IBM SPSS Statistics 21.0 package for Windows (SPSS, Chicago, USA). Data processing and evaluation were performed using Origin 9.0 software (OriginLab Corporation, Northampton, MA, USA). 


\section{Results and discussion}

Total ion chromatograms for Crystal distilled grape spirits were generated by SBSE coupled with GC-MS (Figure 2). Eighty-six volatile compounds were identified and quantified, including 39 esters, 16 volatile alcohols, 14 acids, 4 terpenes, 5 alkanes, 1 benzene derivative, 5 carbonyls and 1 other. Most of these volatile compounds have been previously reported in wines and distilled liquors (Varela et al., 2012). The relative content, retention time (RT), odor threshold and an odor descriptor of each compound were listed in Supplementary file 1.

A total of 42, 46, 49 and 54 aromatic compounds were respectively identified in Crystal distilled grape spirits of $51 \% \mathrm{vol}$, $65 \% \mathrm{vol}, 77 \% \mathrm{vol}$ and $80 \% \mathrm{vol}$ alcohol content, indicating that the number of aromatic compounds increased with the alcohol concentration increasing. Except that, the varieties of aromatic compounds also increased. This result was inconsistent with previous data (Gawel et al., 2007), possibly because of the difference between alcoholic beverages and the difference of raw materials.

The composition and relative amounts of volatile aromatic materials varied in distilled grape spirits with different alcohol concentrations. As is shown in Supplementary file 1 and Figure 3, both the number and content of esters increased significantly with the increase of alcohol concentration, while varieties of acids rose at first and then decreased. These results were similar to those in previous reports (Bartowsky et al., 2008; Knoll et al., 2011). However, the total content of acids showed a dramatic declining trend with an increase in the alcohol content. It has been reported that acids are mainly produced during fermentation (Schreier \& Jennings, 1979). And Knoll et al. (2011) reported that levels of volatile fatty acids such as hexanoic and decanoic acid decreased once malo-lactic fermentation (MLF) had finished, indicating that control of the alcohol concentration cannot be neglected during the distilled spirits making process. Furthermore, no significant changes in volatile alcohols and carbonyls contents were observed, the same as the results reported by others (Knoll et al., 2011). The alkane content increased obviously when the alcohol content was higher than $77 \% \mathrm{vol}$. Benzene derivatives were only detected in $51 \%$ vol and $66 \%$ vol alcohol content spirits. In addition, no terpene was detected in the $80 \%$ vol content spirits. A low contents (lower than 10\%) of volatile alcohols, alkane, benzene derivatives, carbonyls and terpenes were observed in distilled grape spirits with 4 different alcohol contents. Generally, esters and acids were the most abundant groups in the aromatic components of Crystal distilled grape spirits. This is similar to the results from Zhang et al. (2007), who reported that acids were the most abundant aromatic compounds in wine. However, Diéguez et al. (2005) reported that terpenes (like $\beta$-pinene) and volatile alcohols (like citronellol) were intensive for Orujo Spirits. Volatile alcohols were also reported as the primary aroma components for banana spirits (Capobiango et al., 2015), raspberry, strawberry, and mulberry wines (Feng et al., 2015). This means different spirits made out of different materials could be characterized by different properties. Fermentation details, such as yeast species, could also yield totally different results (Zhao et al., 2012).

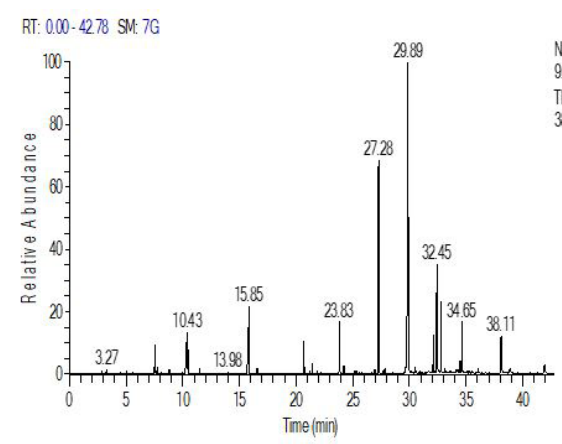

A

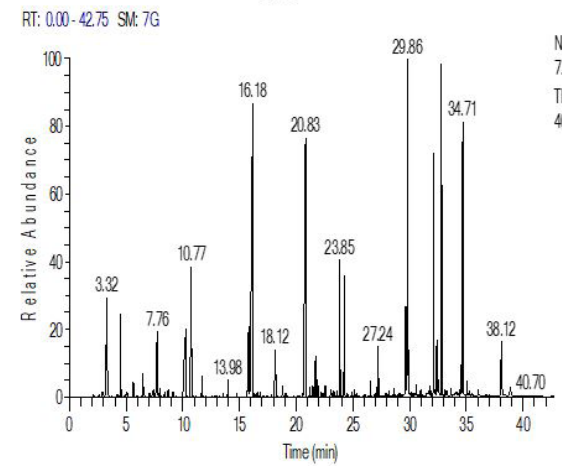

$\mathrm{C}$

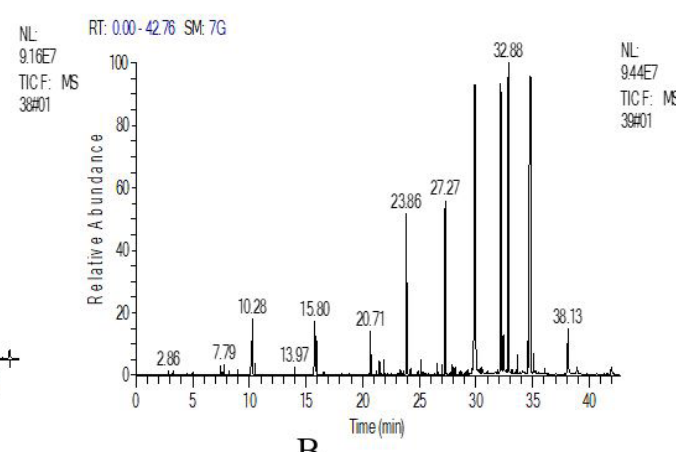

B

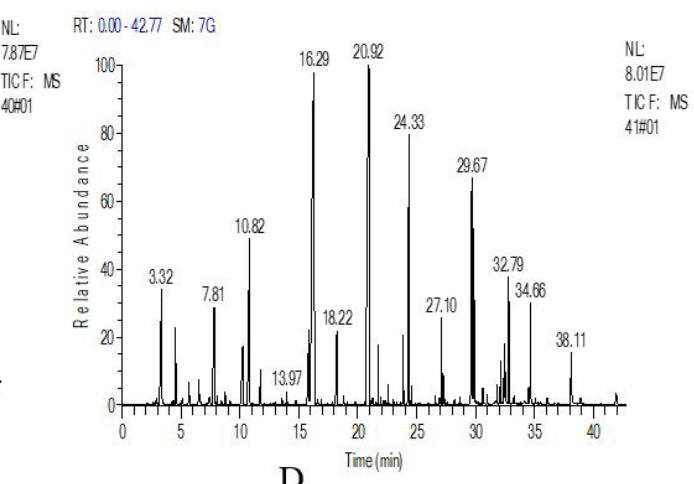

Figure 2. GC-MS total ion chromatogram of aroma components in Crystal distilled grape. Spirits of different alcohol concentration (A) $51 \%$ vol; (B) $65 \%$ vjingol; (C) $77 \%$ vol; (D) $80 \%$ vol. 


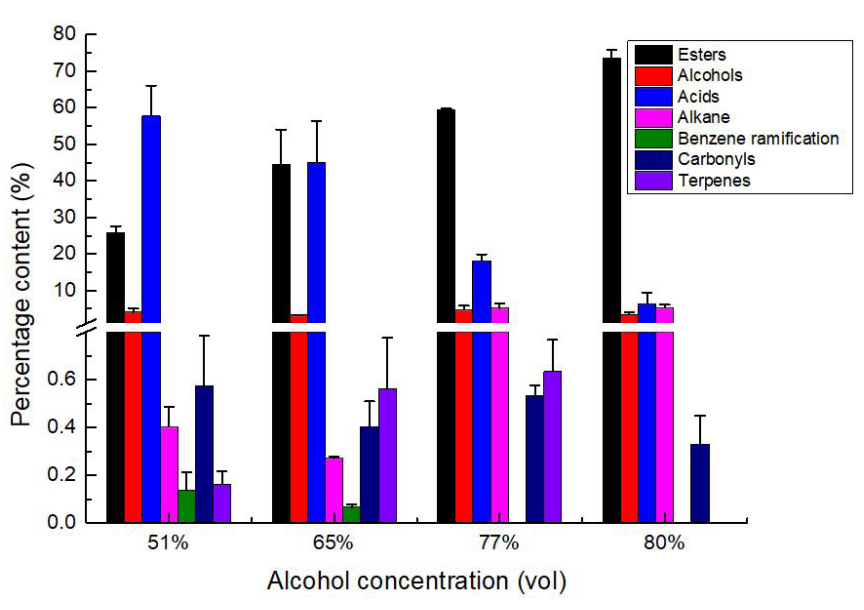

Figure 3. Comparison of aroma compounds contents in distilled grape spirits of different alcohol content.

A total of 19 primary compounds that are important to the flavor development were detected in all Crystal distilled grape spirits with 4 different alcohol concentrations: isomyl acetate, ethyl hexanoate, ethyl caprylate, diethyl succinate, phenylethyl acetate, ethyl laurate, dibutyl phthalate, dipropyl phthalate, isoamylol, trans-9-antihexadecenol, caprylic acid, palmitic acid, palmitoleic acid, pentadecanoic acid, (z,z)-9,12-octadecadienoic acid, myristic acid, dodecanoic acid, capric acid and 1,1-diethoxyethane. Most of these substances have been previously reported by other workers (Varela et al., 2012). Among the 19 primary flavor development materials, the relative percentage contents of ethyl caprylate, dibutyl phthalate and caprylic acid were in the top 10. These compounds were generally considered to have fruity, floral, sweet and fatty aromas in wine (Wen et al., 2014).

Nine similar compounds were detected in the distilled grape spirits at the 4 different alcohol concentrations: ethyl hexanoate, ethyl caprate, ethyl caprylate, terpineol, phenylethyl acetate, ethyl laurate, isoamylol, capric acid and caprylic acid, representing a green apple/strawberry flavor, fatty flavor/fruity flavor, fruity/fennel flavor, lilac flavor, rose flavor, fruity/floral flavor, bitter almond /astringent flavor, rose flavor and cotton candy flavor respectively. Therefore, the characteristic aromas of the Crystal distilled grape spirits were preliminarily identified as rose flavor, strawberry flavor and fruity flavor.

\subsection{Principal Component Analysis (PCA) of volatile compounds}

In order to compare changes of the aromas and to determine potential relationships among the substances measured, principal component analysis (PCA) was employed to identify the components which could be responsible for the aroma content of distilled grape spirits. The number of principal components was determined when the cumulative contribution rate was above $90 \%$.

As Table 2 shown, the cumulative contribution rate of the 3 principal components was $100 \%$, indicating that the contribution rate of the aroma-producing substance was centralized and the cumulative contribution rate increased significantly.
Table 2. Eigenvalues of correlation matrix for the main aroma components.

\begin{tabular}{cccc}
\hline $\begin{array}{c}\text { Principal } \\
\text { component } \\
\text { (PC) }\end{array}$ & Eigenvalue & $\begin{array}{c}\text { Contribution } \\
\text { rat/\% }\end{array}$ & $\begin{array}{c}\text { Summation } \\
\text { percentage } / \%\end{array}$ \\
\hline F1 & 8.9536 & 59.6904 & 59.6904 \\
F2 & 4.6040 & 30.6931 & 90.3834 \\
F3 & 1.4425 & 9.6166 & 100 \\
\hline
\end{tabular}

The characteristic aromas were intense. Furthermore, the cumulative contribution rate of the first 2 principal components accounted for over $90.3834 \%$ of the total variation, indicating that the loss of information of volatile substances in the 4 samples was only $9.6166 \%$. Therefore, F1 and F2 were selected as the cumulative compounds.

Table 3 shows the factor loading matrix of the variables. The first principal component included ethyl hexanoate, ethyl butyrate, ethyl caprate, ethyl caprylate, phenylethyl acetate, ethyl laurate, hexyl acetate, capric acid and caprylic acid, mainly representing the floral flavor, fruity flavor and fatty flavor. The second principal component included terpilenol, (e)-nerolidol, isoamylol and damascenone, mainly representing the rose flavor. Meanwhile, Table 4 showed that the principal components of the aroma compounds in distilled grape spirits at $51 \% \mathrm{vol}, 65 \% \mathrm{vol}, 77 \% \mathrm{vol}$ and $80 \% \mathrm{vol}$ alcohol concentration were F1, F1, F2 and F1, respectively. F2 as the y-coordinate. The PCA indicated that the different aroma components could generally be distinguished based on their volatile composition. As shown in Figure 4, the first two principal components (F1 and F2) explained $59.69 \%$ and $30.69 \%$ of the total variation, respectively. The aroma components were sorted into four main groups in the first and second principal components. Aroma components that affected the distilled grape spirits of $51 \% \mathrm{vol}, 65 \% \mathrm{vol}, 77 \% \mathrm{vol}$ and $80 \% \mathrm{vol}$ alcohol concentration were mainly distributed in the 3, 2, 1 and 4 quadrants, respectively.

The first group of the $51 \% \mathrm{vol}$ alcohol spirits included 2 acids and 1 volatile alcohol, representing unpleasant fat flavor, cheese/stale flavor and cotton candy flavor, respectively. These compounds were located at negative values of both F1 and F2. Components in the $65 \%$ vol group were located at negative values of F1 and positive values of F2. Terpineol was present at a high concentration with lilac flavor, while the concentration of phenylethyl acetate was low and conferred rose flavor (Table 3). Components in the $77 \%$ vol group were located at positive values of both F1 and F2. The concentrations of isoamylol (bitter almond /astringent flavor), damascenone (rose flavor) and (E)-nerolidol (rose/keiskei/apple blossom flavor) were high while the concentration of decanol, conferring a neroli/specific light grease flavor, was slightly lower. The $80 \%$ vol group comprised 6 esters which were located at positive values of F1 and negative values of F2. Concentrations of these components were low and correlated mainly with fruity flavor (Table 3).

In conclusion, the esters were mainly located in the fourth quadrant, while most of the acids presented in the first quadrant (Figure 4), indicating that ester content obviously increased and that the acids significantly decreased with the increasing of alcohol content. The volatile alcohols in the third quadrant were higher 
Wei et al.

Table 3. Loading and contribution rate matrix of the principal components.

\begin{tabular}{|c|c|c|c|c|c|c|}
\hline \multirow{2}{*}{ Variates } & \multicolumn{2}{|c|}{ Factor loadings } & \multicolumn{2}{|c|}{ Contribution rate $/ \%$} & \multirow{2}{*}{ Odor description } & \multirow{2}{*}{ Aromatic series } \\
\hline & $\mathrm{F} 1$ & F2 & F1 & $\mathrm{F} 2$ & & \\
\hline Ethyl hexanoate & 0.939 & -0.255 & 9.851 & 1.413 & Green apple, strawberry & Fruity \\
\hline Ethyl butyrate & 1 & 0.019 & 11.165 & 0.007 & Fruity, strawberry & Fruity \\
\hline Ethyl caprate & 0.995 & -0.095 & 11.065 & 0.197 & Fatty, fruity & Fatty, fruity \\
\hline Ethyl caprylate & 0.951 & -0.215 & 10.101 & 1.006 & Fruity, sweet, floral & Fruity, floral, sweet \\
\hline Decanol & 0.656 & 0.650 & 4.811 & 9.181 & Neroli, specific light grease & Citrusy, floral, fatty \\
\hline Terpilenol & -0.551 & 0.813 & 3.392 & 14.356 & Lilac & Floral \\
\hline (E)-nerolidol & 0.353 & 0.804 & 1.391 & 14.035 & Rose, orange, apple blossom & Floral, citrusy \\
\hline Phenylethyl acetate & -0.861 & 0.465 & 8.281 & 4.701 & Rose, fruity, honey & Floral, sweet, floral \\
\hline Ethyl laurate & 0.921 & -0.347 & 9.474 & 2.618 & Fruity, floral & Fruity, floral \\
\hline Hexyl acetate & 0.896 & -0.364 & 8.971 & 2.871 & Pleasant fruity, pear, floral & Fruity, floral \\
\hline Isoamylol & 0.134 & 0.952 & 0.201 & 19.695 & Bitter almond, astringent & Chemical \\
\hline Capric acid & -0.946 & -0.210 & 9.997 & 0.954 & Unpleasant fatty & Fatty \\
\hline Caprylic acid & -0.762 & -0.463 & 6.489 & 4.553 & Cheese, stale, fatty & Fatty, sweet, chemical \\
\hline Damascenone & 0.357 & 0.905 & 1.426 & 17.778 & Rose & Floral \\
\hline 3-Furfuryl alcohol & -0.55 & -0.548 & 3.384 & 6.525 & Cotton candy & Sweet \\
\hline
\end{tabular}

Table 4. Factor scores and contribution rates for distilled grape spirits of 4 alcohol concentrations.

\begin{tabular}{|c|c|c|c|c|c|c|}
\hline \multirow{2}{*}{ Samples } & \multicolumn{2}{|c|}{ Factor scores } & \multicolumn{2}{|c|}{ Contribution rate/\% } & \multicolumn{2}{|c|}{ Squared cosines } \\
\hline & $\mathrm{F} 1$ & $\mathrm{~F} 2$ & F1 & F2 & F1 & F2 \\
\hline $51 \%$ vol & -2.853 & -2.037 & 22.725 & 22.531 & 0.581 & 0.296 \\
\hline $65 \% \mathrm{vol}$ & -2.938 & 1.088 & 24.104 & 6.433 & 0.697 & 0.096 \\
\hline 77\%vol & 1.829 & 2.987 & 9.342 & 48.463 & 0.252 & 0.673 \\
\hline $80 \% \mathrm{vol}$ & 3.962 & -2.039 & 43.828 & 22.573 & 0.771 & 0.204 \\
\hline
\end{tabular}

Scatter diagrams were made with the $\mathrm{F} 1$ principal component value as the $\mathrm{x}$-coordinate.

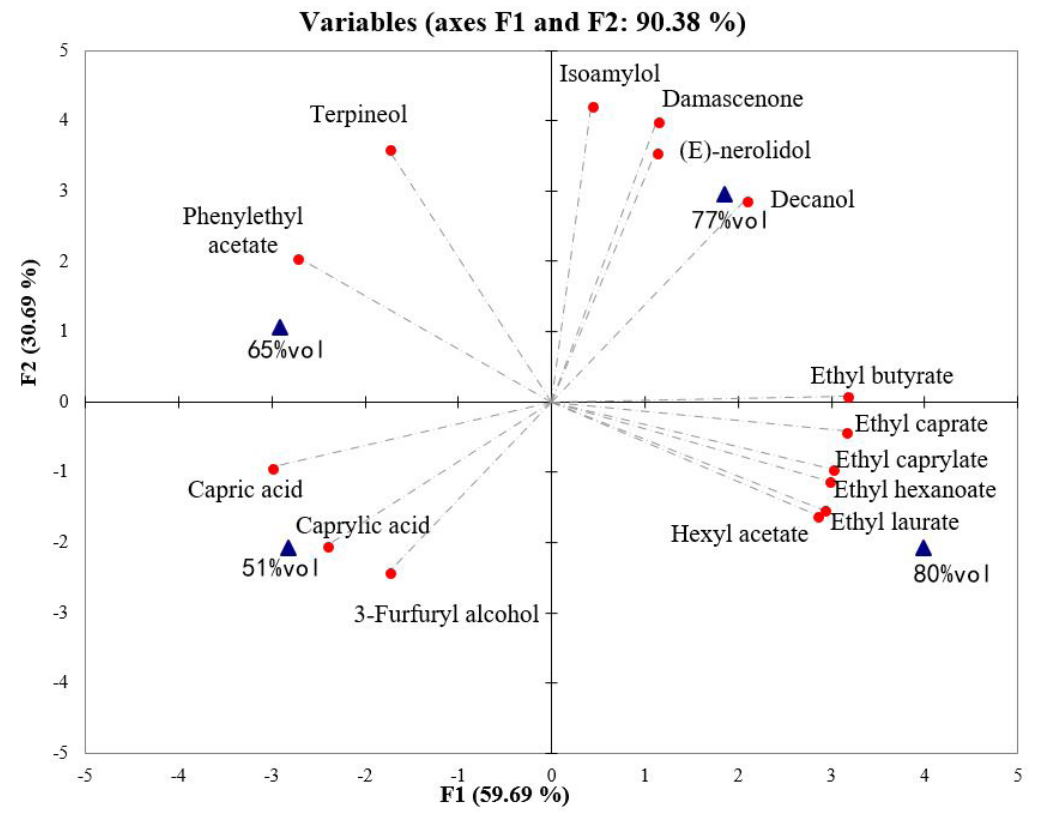

Figure 4. Scatter plot for the principal component analysis of aroma character of distilled grape spirits.

than that in the other quadrants, indicating that the content of volatile alcohols in sample of $77 \% \mathrm{vol}$ alcohol concentration was higher than the others. Aroma components that affected the distilled grape spirits of $51 \% \mathrm{vol}$ alcohol concentration were mainly an unpleasant fat flavor and a cheese flavor, while the $65 \% \mathrm{vol}$ sprit was characterized by floral flavor. Rose flavor, apple blossom flavor and neroli flavor were the main flavors in $77 \%$ vol spirit while fruity and floral flavors were obvious in $80 \%$ vol 
spirits. These were similar to the previous studies, in which the floral and fruity flavors were also described as the main aroma characteristics (Diéguez et al., 2005; Zhao et al., 2012).

\subsection{Variation analysis and evaluation of odor profiles}

Compounds with similar odor description were grouped, and six aromatic series of odors were established (Table 3 ). Variation analysis and evaluation of odor profiles were shown in Figure 5. The fruity was the strongest in the 6 aromatic series, followed by floral, then fatty. This result was consistent with previous data for spirits and brandies (Diéguez et al., 2005; Zhao et al., 2012). For instance, Diéguez et al. (2005) reported that herbaceous, floral and fruity were strong in Commercial Galician Orujo Spirits, while Zhao et al. (2012) found that fruity and floral were typical odor profiles for freshly distilled Chinese brandy. Same phenomenon can also be found for some wines and cultivars (Wen et al., 2014; Serradilla et al., 2010). There may also be some little differences in the spirits odor profiles for different samples. For example, expect fruity, odors of vanilla, woody and green were also said critical for the aroma of brandy (Caldeira et al., 2002). It is possibly because of the different materials, brewing environment, time and the techniques adapted, such as the ripening processing in oak barrel (Li \& Beta, 2011). Wen et al. (2014) reported that green was the most intense odor characteristic followed by floral and citrusy odors in cherries.

The 51\%vol alcohol concentration treatment enhanced the fatty, chemical and sweet characteristics, but contents of fruity and floral flavors were low. Fatty, cheese and bitter almond flavors have important effects on the aroma characteristics of this sample. Fatty, chemical and sweet characteristics are mainly due to acids, esters and volatile alcohols such as capric acid, caprylic acid, phenylethyl acetate and isoamylol. A low concentration of acids will give the liquor light pleasant fragrance, but an excess concentration of acids may have a negative effect on the wine aroma quality (Fariña et al., 2015). In sample of 65\%vol alcohol concentration, the fatty, sweet and chemical characteristics

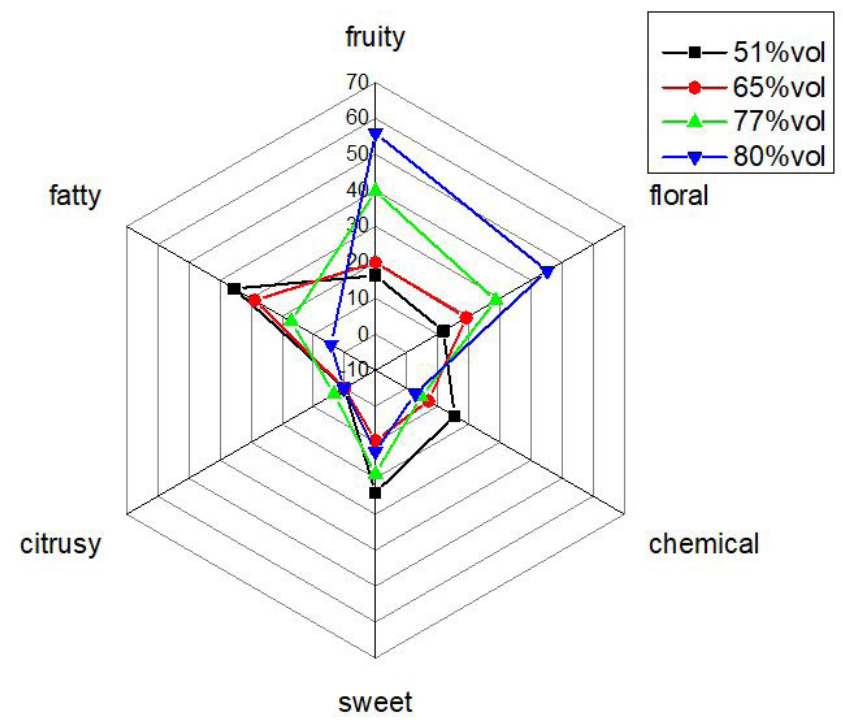

Figure 5. Radar map of aromatic series for the distilled grape spirits of different alcohol concentrations. were weaker than those in the $51 \% \mathrm{vol}$ spirits, and a higher odor intensity of fruity and floral was observed. This was in agreement with the findings of previous research that alcohol can alter the perception of 'sweetness' (Nurgel \& Pickering, 2006). Meillon et al. (2010) also reported an increase in 'harmony' of red wine with a partial alcohol reduction, which is the same as the findings in this study. Spirits of $65 \% \mathrm{vol}$ alcohol content were more fragrant than the 51\%vol. Capric acid (fatty) and phenylethyl acetate (fruity, floral and sweet) made an important contribution to the flavors in distilled spirits (Table 3). Damascenone and terpineol made a positive contribution to the integral aroma of the $65 \% \mathrm{vol}$ alcohol content spirits. However, the contributions of all 6 aroma series to liquor aroma were relatively low in general. Accordingly, the odor characteristics were not very obvious. Esters, such as ethyl caprylate and ethyl decylate, were the main volatile aroma substances in distilled grape spirits of $80 \% \mathrm{vol}$ alcohol. Floral and fruity flavors were also very strong but the content of the other odor series was low. This result was inconsistent with previous results of King et al. (2013) that alcohol reduced the perception of the floral aroma while enhancing the chemical aroma. There was a maldistribution of aroma substances in this sample. The elements of the aroma were simple and the distilled spirits were not fragrant.

A higher content and a greater variety of esters in the $77 \% \mathrm{vol}$ alcohol spirits made the floral odor richer and more complex. A small quantity of acid contributed freshness to the overall aroma. A significant drop in fatty and chemical odors is indicated in Figure 5. The floral and fruity aroma obviously increased as the alcohol concentration decreased, confirming the results of Meillon et al. (2010) that the removal of alcohol from wine also reduced the 'fruity' aroma. However, Goldner et al. (2009) and King et al. (2013) reported that ethanol suppresses the 'fruity' aroma. The flavors of rose and apple, mainly from ethyl decylate and ethyl caprylate, became the main aroma in the distilled spirits. The contents of all 6 aromatic series of odors were moderate and complementary, making the overall aroma rich and balanced.

\section{Conclusions}

In this study, significant differences in the odor profiles, aroma content and varieties of different samples were observed. The ester content increased with the alcohol concentration increasing, while the acid content dramatically decreased. No terpene was found in of $80 \% \mathrm{vol}$ alcohol spirits, and alkanes increased obviously in $77 \%$ vol alcohol spirits. Fruity was the strongest of the 6 aromatic series of odor and distilled grape spirits and the spirit of $77 \% \mathrm{vol}$ alcohol content was the most fragrant with complex and moderate aromatic odors. The control of the alcohol concentration in distilled spirits making process was confirmed to be critical and beneficial to the formation of the aroma substances. Volatiles in spirits, which were made from the same homogenized grapes, showed significant differences in some respects. It's interesting and unusual to some extent. Further systematic experiments are necessary to study the influencing mechanism of alcohol on the volatiles and to determine the optimal alcohol concentration for the production of distilled Crystal grape spirits. Besides, the thresholds change dramatically 
with different alcohol levels, more research is needed to study the thresholds properties of the distilled Crystal grape spirits. Except that, it is also necessary to assess whether these effects are similar for other distilled spirits.

\section{References}

Bartowsky, E., Costello, P. J., \& McCarthy, J. M. (2008). MLF-adding an 'extra dimension' to wine flavour and quality. The Australian \& New Zealand Grapegrower \& Winemaker, 533, 60-65.

Caldeira, I., Belchior, A. P., Clímaco, M. C., \& Sousa, R. (2002). Aroma profile of Portuguese brandies aged in chestnut and oak woods. Analytica Chimica Acta, 458(1), 55-62. http://dx.doi.org/10.1016/ S0003-2670(01)01522-7.

Caldeira, I., Santos, R., Ricardo-da-Silva, J. M., Anjos, O., Mira, H., Belchior, A. P., \& Canas, S. (2016). Kinetics of odorant compounds in wine brandies aged in different systems. Food Chemistry, 211, 937-946. http://dx.doi.org/10.1016/j.foodchem.2016.05.129. PMid:27283715.

Capobiango, M., Mastello, R. B., Chin, S. T., Oliveira, E. S., Cardeal, Z. L., \& Marriott, P. J. (2015). Identification of aroma-active volatiles in banana Terra spirit usingmultidimensional gas chromatography with simultaneous massspectrometry and olfactometry detection. Journal of Chromatography. A, 1388, 227-235. http://dx.doi.org/10.1016/j. chroma.2015.02.029. PMid:25728661.

Customs Information China. (2016). Import and export statistics of distilled grape spirits for China. China. Retrieved from http://www. haiguan.info/

Delgado, R., Durán, E., Castro, R., Natera, R., \& Barroso, C. G. (2010). Development of a stir bar sorptive extraction method coupled to gas chromatography-mass spectrometry for the analysis of volatile compounds in Sherry brandy. Analytica Chimica Acta, 672(1-2), 130-136. http://dx.doi.org/10.1016/j.aca.2010.05.015. PMid:20579501.

Diéguez, S. C., De la Peña, M. L., \& Gómez, E. F. (2003). Approaches to spirit aroma: contribution of some aromatic compounds to the primary aroma in samples of orujo spirits. Journal of Agricultural and Food Chemistry, 51(25), 7385-7390. http://dx.doi.org/10.1021/ jf0302916. PMid:14640588.

Diéguez, S. C., De la Peña, M. L., \& Gómez, E. F. (2005). Volatile composition and sensory characters of commercial galician orujo spirits. Journal of Agricultural and Food Chemistry, 53(17), 67596765. http://dx.doi.org/10.1021/jf040467j. PMid:16104796.

Fan, W., Xu, Y., \& Yu, A. (2006). Influence of oak chips geographical origin, toast level, dosage and aging time on volatile compounds of apple cider. Journal of the Institute of Brewing, 112(3), 255-263. http://dx.doi.org/10.1002/j.2050-0416.2006.tb00721.x.

Fariña, L., Villar, V., Ares, G., Carrau, F., Dellacassa, E., \& Boido, E. (2015). Volatile composition and aroma profile of Uruguayan Tannat wines. Food Research International, 69, 244-255. http://dx.doi. org/10.1016/j.foodres.2014.12.029.

Feng, Y., Liu, M., Ouyang, Y. N., Zhao, X. F., Ju, Y. L., \& Fang, Y. L. (2015). Comparative study of aromatic compounds in fruit wines from raspberry, strawberry, and mulberry in central Shaanxi area. Food \& Nutrition Research, 59(1), 1-10. http://dx.doi.org/10.3402/ fnr.v59.29290. PMid:26617387.

Fiches, G., Déléris, I., Saint-Eve, A., Brunerie, P., \& Souchon, I. (2013). Modifying PTR-MS operating conditions for quantitative headspace analysis of hydro-alcoholic beverages. 2. Brandy characterization and discrimination by PTR-MS. International Journal of Mass Spectrometry, 360, 15-23. http://dx.doi.org/10.1016/j.ijms.2013.11.010.
Fontoin, H., Saucier, C., Teissedre, P. L., \& Glories, Y. (2008). Effect of $\mathrm{pH}$, ethanol and acidity on astringency and bitterness of grape seed tannin oligomers in model wine solution. Food Quality and Preference, 19(3), 286-291. http://dx.doi.org/10.1016/j.foodqual.2007.08.004.

Gawel, R., Sluyter, S. V., \& Waters, E. J. (2007). The effects of ethanol and glycerol on the body and other sensory characteristics of Riesling wines. Australian Journal of Grape and Wine Research, 13(1), 38-45. http://dx.doi.org/10.1111/j.1755-0238.2007.tb00070.x.

Geroyiannaki, M., Komaitis, M. E., Stavrakas, D. E., Polysiou, M., Athanasopoulos, P. E., \& Spanos, M. (2007). Evaluation, of acetaldehyde and methanol in greek traditional alcoholic beverages from varietal fermented grape pomaces (Vitis vinifera L.). Food Control, 18(8), 988-995. http://dx.doi.org/10.1016/j.foodcont.2006.06.005.

Goldner, M. C., Zamora, M. C., Di Leo Lira, P., Gianninoto, H., \& Bandoni, A. (2009). Effect of ethanol level in the perception of aroma attributes and the detection of volatile compounds in red wine. Journal of Sensory Studies, 24(2), 243-257. http://dx.doi. org/10.1111/j.1745-459X.2009.00208.x.

Janáčová, A., Sádecká, J., Kohajdová, Z., \& Špánik, I. (2008). The identification of aroma-active compounds in slovak brandies using GC-Sniffing, GC-MS and sensory evaluation. Chromatographia, 67(1, Suppl.), 113-121. http://dx.doi.org/10.1365/s10337-008-0635-1.

King, E. S., Dunn, R. L., \& Heymann, H. (2013). The influence of alcohol on the sensory perception of red wines. Food Quality and Preference, 28(1), 235-243. http://dx.doi.org/10.1016/j.foodqual.2012.08.013.

Knoll, C., Fritsch, S., Schnell, S., Grossmann, M., Rauhut, D., \& Du Toit, M. (2011). Influence of $\mathrm{pH}$ and ethanol on malolactic fermentation and volatile aroma compound composition in white wines. Lebensmittel-Wissenschaft + Technologie, 44(10), 2077-2086. http://dx.doi.org/10.1016/j.lwt.2011.05.009.

Li, W., \& Beta, T. (2011). Evaluation of antioxidant capacity and aroma quality of anthograin liqueur. Food Chemistry, 127(3), 968-975. http://dx.doi.org/10.1016/j.foodchem.2011.01.066. PMid:25214085.

Meillon, S., Viala, D., Medel, M., Urbano, C., Guillot, G., \& Schlich, P. (2010). Impact of partial alcohol reduction in Syrah wine on perceived complexity and temporality of sensations and link with preference. Food Quality and Preference, 21(7), 732-740. http:// dx.doi.org/10.1016/j.foodqual.2010.06.005.

Nurgel, C., \& Pickering, G. (2006). Modeling of sweet, bitter and irritant sensations and their interactions elicited by model ice wines. Journal of Sensory Studies, 21(5), 505-519. http://dx.doi.org/10.1111/j.1745459X.2006.00081.x.

Okutsu, K., Yoshizaki, Y., Kojima, M., Yoshitake, K., Tamaki, H., \& Kazunori, T. (2015). Effects of the cultivation period of sweet potato on the sensory quality of imo-shochu, a Japanese traditional spirit. Journal of the Institute of Brewing, 122(1), 168-174. http://dx.doi. org/10.1002/jib.305.

Pickering, G. J., Heatherbell, D. A., Vanhanen, L., \& Barnes, M. F. (1998). The Effect of Ethanol Concentration on the Temporal Perception of Viscosity and Density in White Wine. American Journal of Enology and Viticulture, 49, 306-318.

Porto, C. D., \& Decorti, D. (2010). Countercurrent supercritical fluid extraction of grape-spirit. The Journal of Supercritical Fluids, 55(1), 128-131. http://dx.doi.org/10.1016/j.supflu.2010.08.016.

Rota, M. B., Piggott, J. R., \& Faria, J. B. (2013). Sensory profile and acceptability of traditional and double-distilled cachaça aged in oak casks. Journal of the Institute of Brewing, 119(4), 251-257. http:// dx.doi.org/10.1002/jib.88.

Saénz-Navajas, M. P., Ballester, J., Pêcher, C., Peyron, D., \& Valentin, D. (2013). Sensory drivers of intrinsic quality of red wines: Effect 
of culture and level of expertise. Food Research International, 54(2), 1506-1518. http://dx.doi.org/10.1016/j.foodres.2013.09.048.

Satora, P., \& Tuszynski, T. (2010). Influence of indigenous yeasts on the fermentation and volatile profile of plum brandies. Food Microbiology, 27(3), 418-424. http://dx.doi.org/10.1016/j.fm.2009.12.005. PMid:20227608.

Schreier, P., \& Jennings, W. G. (1979). Flavor composition of wines: a view. Critical Reviews in Food Science and Nutrition, 12(1), 59-111. http://dx.doi.org/10.1080/10408397909527273. PMid:389563.

Serradilla, M. J., Martín, A., Hernandez, A., López-Corrales, M., Lozano, M., \& Córdoba, M. G. (2010). Effect of the commercial ripening stage and postharvest storage on microbial and aroma changes of 'Ambrunés' sweet cherries. Journal of Agricultural and Food Chemistry, 58(16), 9157-9163. http://dx.doi.org/10.1021/ jf102004v. PMid:23654239.

Soto, M. L., Moure, A., Domínguez, H., \& Parajó, J. C. (2008). Charcoal adsorption of phenolic compounds present in distilled grape pomace. Journal of Food Engineering, 84(1), 156-163. http://dx.doi. org/10.1016/j.jfoodeng.2007.04.030.

Varela, C., Torrea, D., Schmidt, S. A., Ancin-Azpilicueta, C., \& Henschke, P. A. (2012). Effect of oxygen and lipid supplementation on the volatile composition of chemically defined medium and Chardonnay wine fermented with Saccharomyces cerevisiae. Food Chemistry, 135(4), 2863-2871. http://dx.doi.org/10.1016/j.foodchem.2012.06.127. PMid:22980883.

Wang, J., Kassab, C., Harbor, J. M., Caffee, M. W., Cui, H., \& Zhang, G. L. (2013). Cosmogenic nuclide constraints on late Quaternary glacial chronology on the Dalijia Shan, northeastern Tibetan Plateau. Quaternary Research, 79(03), 439-451. http://dx.doi.org/10.1016/j. yqres.2013.01.004.

Wen, Y. Q., He, F., Zhu, B. Q., Lan, Y. B., Pan, Q. H., Li, C. Y., Reeves, M. J., \& Wang, J. (2014). Free and glycosidically bound aroma compounds in cherry (Prunus avium L.). Food Chemistry, 152, 29-36. http://dx.doi.org/10.1016/j.foodchem.2013.11.092. PMid:24444903.
Zhang, M., Xu, Q., Duan, C., Qu, W., \& Wu, Y. (2007). Comparative study of aromatic compounds in young red wines from Cabernet Sauvignon, cabernet franc, and cabernet gernischt varieties in China. Journal of Food Science, 72(5), E248-E252. http://dx.doi. org/10.1111/j.1750-3841.2007.00357.x.

Zhang, Q. X., Du, J. H., Jin, Y. H., Zhao, Z. Y., \& Li, Y. Y. (2013a). $\mathrm{SO}_{2}$ reduction in distilled grape spirits by three methods. Journal of the Institute of Brewing, 119(4), 314-320. http://dx.doi.org/10.1002/jib.100.

Zhang, W. J., Jin, F. F., Zhao, J. X., Qi, L., \& Ren, H.-L. (2013b). The possible influence of a nonconventional El Niño on the severe autumn drought of 2009 in southwest China. Journal of Climate, 26(21), 8392-8405. http://dx.doi.org/10.1175/JCLI-D-12-00851.1.

Zhang, Y. F., Huang, H. P., Peng, S. J., Ren, Z., Chen, Z. B., Liu, J. N., et al (2015). Effects of salicylic acid on growth and nutrition accumulation of Shuijing seedling under aluminum stress. SINOOVERSEAS GRAPEVINE \& WINE, 2, 10-15.

Zhang, Y., Zhao, Y. C., Shi, X. Z., Lu, X. X., Yu, D. S., Wang, H. J., Sun, W. X., \& Darilek, J. L. (2008). Variation of soil organic carbon estimates in mountain regions: a case study from Southwest China. Geoderma, 146(3-4), 449-456. http://dx.doi.org/10.1016/j.geoderma.2008.06.015.

Zhao, Y. P., Li, J. M., Zhang, B. C., Yu, Y., Shen, C. H., \& Song, P. (2012). A comparison of the influence of eight commercial yeast strains on the chemical and sensory profiles of freshly distilled Chinese brandy. Journal of the Institute of Brewing, 118(3), 315-324. http:// dx.doi.org/10.1002/jib.44.

Zhao, Y., Xu, Y., Li, J., Fan, W., \& Jiang, W. (2009). Profile of volatile compounds in 11 brandies by headspace solid-phase microextraction followed by gas chromatography-mass spectrometry. Journal of Food Science, 74(2), 90-99. http://dx.doi.org/10.1111/j.17503841.2008.01029.x. PMid:19323737.

Zheng, X. B., Kang, W. M., Zhao, T. L., Luo, Y. X., Duan, C. C., \& Chen, J. (2008). Long-term trends in sunshine duration over Yunnan-Guizhou Plateau in Southwest China for 1961-2005. Geophysical Research Letters, 35(15), 386-390. http://dx.doi.org/10.1029/2008GL034482. 